\title{
DNA (Cytosine-5)-Methyltransferase 1
}

National Cancer Institute

\section{Source}

National Cancer Institute. DNA (Cytosine-5)-Methyltransferase 1. NCI Thesaurus. Code C73690.

DNA (cytosine-5)-methyltransferase 1 protein (1613 aa, 183 kDa) is encoded by the human DNMT 1 gene. This soluble, nuclear protein is involved in epigenetic modification of chromatin, catalyzing the methylation of $\mathrm{C} 5$ in $\mathrm{CpG}$ dinucleotides within DNA. 